\title{
Fruit Qualities of Interspecific Hybrid and First Backcross Generations between Red Raspberry and Rubus parvifolius
}

\author{
Saki Toshima \\ Interdisciplinary Graduate School of Agriculture and Engineering, University of Miyazaki, \\ 1-1 Gakuenkibanadainishi, Miyazaki-shi, Miyazaki 889-2192, Japan

\begin{abstract}
Marika Fujii, Momoko Hidaka, Soya Nakagawa, Tomonari Hirano, and Hisato Kunitak Faculty of Agriculture, University of Miyazaki, 1-1 Gakuenkibanadainishi, Miyazaki-shi, Miyazaki 889-2192, Japan
\end{abstract}

AdDitional INDEX wORDs. anthocyanin, carotenoid, Japanese wild species, primocane-fruiting, sugar

\begin{abstract}
Interspecific hybridization is useful in raspberry (Rubus idaeus L. ssp. idaeus) breeding to introgression of traits such as heat or cold tolerance, and excellent fruit qualities. Rubus L. wild species in Asia, including Rubus parvifolius $\mathrm{L}$., have been attracting a great deal of attention as sources of new traits in breeding raspberry and blackberry (Rubus fruticosus Agg.). We previously developed and selected IPI-1 and IPI-3 first backcross $\left(\mathrm{BC}_{1}\right)$ hybrids, ['Indian Summer' $(R$. idaeus ssp. idaeus) $\times R$. parvifolius] $\times$ 'Indian Summer', as raspberry cultivars adapted to the warm climate in parts of Japan. In this study, we investigated the growth, morphological traits, and fruit qualities, such as sugar, organic acid, anthocyanins, and carotenoids, of each of these IPI lines over a 2-year period to discern their potential as commercial raspberry cultivars. IPI lines had the characteristic of primocane fruit with overflowing from side buds while the parent, IP-1 ('Indian Summer' $\times$ R. parvifolius), did not. IPI lines showed significantly lower values in anthocyanin content than red raspberry 'Skeena', while showing higher carotenoid contents. This study is the first research about fruit qualities such as anthocyanin and carotenoid content of $\mathrm{BC}_{1}$ hybrids using Japanese wild Rubus species.
\end{abstract}

Rubus (Rosaceae) comprises more than 740 species with additional commercially cultivated raspberry $(R$. idaeus ssp. idaeus) and blackberry (R. fruticosus) (Gu et al., 1990). The fruit are used as ingredients in fresh dishes and processed products such as jams and juices. Raspberry and blackberry were first grown commercially in Europe in the mid-16th century, and the breeding of raspberry began in the 18th century (Jennings, 1995). A total of 187 red raspberry and 75 blackberry cultivars were newly released in the 20-year period from 1994 to 2014 (Clark et al., 2008; Finn and Clark, 2014; Moore and Kempler, 2012). Cultivars with various colors of fruit such as red, black, purple, and yellow have been developed through cross- and mutation-breeding processes. Also, raspberry cultivars can be divided into two types according to the characteristics of fruit sets, floricane (FC)-fruiting, and primocane (PC)-fruiting (Heide and Sønsteby, 2011). PC-fruiting cultivars go through the whole cane growth, flowering, and fruiting cycle during one growing season, producing most fruit late in the fall on PCs, whereas the more traditional FC-fruiting cultivars produce fruit in early summer, on buds of second-year canes. Therefore, the character of PC fruiting has recently become an important breeding objective, because PC-fruiting cultivars have higher yields. As described

Received for publication 27 July 2021. Accepted for publication 9 Sept. 2021.

Published online 22 October 2021

This project was supported by a Kawaminami-cho (Miyazaki Prefecture, Japan) Industry-Academia-Government Collaboration Project (2016-19). We thank Mr Ushio Sakazaki (Flora Twenty-One Co., Ltd., Japan) for his significant contributions to this study.

H.K. is the corresponding author. E-mail: hkuni@cc.miyazaki-u.ac.jp.

This is an open access article distributed under the CC BY-NC-ND license (https://creativecommons.org/licenses/by-nc-nd/4.0/). previously, raspberry is classified into several types not only by fruit color but also fruiting habits.

In recent years, the bioactive compounds of the fruit of Rubus cultivars and wild species and their functions have been extensively analyzed. Numerous bioactive components such as phenolics, flavonols, anthocyanins, and as some vitamins have been identified in the fruit of Rubus cultivar and wild species, and shown to have health-promoting effects (Alibabic et al., 2018; Burton-Freeman et al., 2016; Yang et al., 2020). In particular, anthocyanins and carotenoids are involved in the color of the raspberry and blackberry pigments, such as black, red, and yellow (Carvalho et al., 2013; de Ancos et al., 1999; Toshima et al., 2021). Most of the research on raspberry has focused on compounds such as anthocyanins, ellagitannins, and vitamin $\mathrm{C}$ in the fruit (Skrovankova et al., 2015; Szajdek and Borowska, 2008). While Marinova and Ribarova (2007) demonstrated that the carotenoid content in raspberry and blackberry fruit was higher than that of strawberry (Fragaria vesca L.), blueberry (Vaccinium myrtillus L.), and red currant (Ribes rubrum L.), there is still relatively little information about the content and composition of carotenoids in Rubus species.

Interspecific hybridization is useful in breeding cultivars resistant to biotic and abiotic stresses (Dai et al., 2015; Stanys et al., 2019). Traits such as heat or cold tolerance, disease resistance, and fruit qualities are very important for the breeding of raspberry and blackberry (Clark et al., 2012; Molina-Bravo et al., 2014; Pritts, 2008). Some raspberry cultivars developed in North America, such as Esta and Kitsilano, have benefited greatly from interspecific hybridization using Asian Rubus wild species (Hummer et al., 2013). Indeed, interspecific hybridization using wild Rubus species promises further useful cultivars. Toshima et al. (2017) developed the '07RUBIXP01' (IP-1) 
hybrid, registered in 2012 as No. 21801 under the Seed and Seedling Law in Japan, between 'Indian Summer' red raspberry and the eastern Asia wild species $R$. parvifolius. However, the IP-1 interspecific hybrid has shown problems with prickles and large drupelets that prevent the development of well-formed fruit. Therefore, we carried out a backcross between IP-1 and 'Indian Summer' red raspberry, and selected the $10 \mathrm{BC}_{1}$ generations for use in hot climates, and indeed, they proved capable of being cultivated well even in the warm southern part of the Kyushu region, Japan. Furthermore, the two strains with highly fertile and forming sufficient aggregate fruit, namely $\mathrm{BC}_{1}-1$ and $\mathrm{BC}_{1}-3$, called IPI-1 and IPI-3, could be selected from $10 \mathrm{BC}_{1}$ generations that were confirmed to grow vigorously. However, data on the morphological characteristics and fruit composition of these $\mathrm{BC}_{1}$ generations, IPI- 1 and IPI-3, have not yet been collected and analyzed.

In this study, therefore, we investigated the morphological traits and fruit contents of sugar, organic acid, anthocyanins, and carotenoids of IPI-1 and IPI-3 to explore their potential as commercial raspberry cultivars.

\section{Materials and Methods}

Plant materials. $\mathrm{BC}_{1}$ hybrids IPI-1 and IPI-3, ['Indian Sumer' (R. idaeus ssp. idaeus) $\times$ R. parvifolius $] \times$ 'Indian Sumer', were investigated for growth characteristics and anthocyanin and carotenoid contents of mature fruit. A female of the parent of IPI1 and IPI-3, IP-1 (three mature plants, 'Indian Summer' $\times$ R. parvifolius) and two red raspberry cultivars, Indian Summer and Skeena (three mature plants each), were used as controls. These plants were propagated by softwood cuttings in a ventilated highhumidity "fog" system, and emerging shoots with new roots were individualized and planted in plug trays. One-year-old plants were planted on each three plants on 17 Dec. 2016 on the experimental farm at Kimura Agristream Co., Ltd., in Kawaminamicho (lat. $32^{\circ} 14^{\prime} 21.2^{\prime \prime} \mathrm{N}$, long. $131^{\circ} 30^{\prime} 55.6^{\prime \prime} \mathrm{E}$ ), Miyazaki Prefecture. Plants were spaced at $2 \mathrm{~m}$ between rows in an unheated plastic greenhouse $(6.5 \times 30 \mathrm{~m})$. Fundamental cultivation methods were carried out according to a guideline for plastic greenhouse cultivation (Imanishi and Miyairi, 2015). Flowering and harvesting periods of interspecific hybrid IP-1, the $\mathrm{BC}_{1}$ hybrids, IPI-1 and IPI-3, and 'Indian Summer' were observed in 2017. Three main experiments for the growth characteristics and anthocyanin and carotenoid contents of mature fruit were conducted in the years 2018 and 2019. Because it is difficult to cultivate the red raspberry 'Indian Summer' for more than 2 years in this area, the fruit of 'Skeena' was used for the analysis. A randomized complete block design with three replications was used for the experiments.

For analyses of components in fruit, FC and PC fruit were harvested separately in 2018 and 2019, and were frozen to a temperature of $-40^{\circ} \mathrm{C}$ and freeze-dried in a lyophilizer (FDU-1100; Tokyo Rikakikai, Tokyo, Japan) and a chamber (DRC-1000, Tokyo Rikakikai). After drying, freeze-dried samples were crushed with a pulverizer (B-400; Nihon Buchi, Tokyo, Japan) and stored at $-40^{\circ} \mathrm{C}$ until used in experiments.

Fruit characteristics. FC and PC fruit of IPI lines and 'Indian Summer' were harvested in 2019 and analyzed for six characteristics. Per-berry weight and average length and diameter (measured by caliper), number of drupelets per berry, and average weight of drupelets were measured from 10 fruit that were picked randomly from each of three plants of the IPI lines and 'Indian Summer', and the average weight of seeds per berry was determined from three fruit picked randomly from each three plants.

Sugars AND ORGANIC ACIDS. Sugar and organic acid contents were determined by high-performance liquid chromatography (HPLC). Freeze-dried fruit $(0.02 \mathrm{~g})$ were dissolved in $5 \mathrm{~mL}$ ultrapure water and passed through a $0.22-\mu \mathrm{m}$ membrane filter (Millipore, Bedford, MA) for analyses. For sugar content, the extracts were analyzed by HPLC using a UF-Amino station system (Shimazu, Kyoto, Japan) and refractive index detector (RID-10A, Shimadzu) with Asahipak NH2P-50 4E (Showadenko, Tokyo, Japan). The chromatographic conditions were as follows: solvent, $75 \%(\mathrm{v} / \mathrm{v})$ acetonitrile; column temperature, $40^{\circ} \mathrm{C}$; flow rate, $1.0 \mathrm{~mL} \cdot \mathrm{min}^{-1}$. Retention times and spectra were compared with those of pure standards of glucose, fructose, and sucrose. For organic acid content, the extracts were analyzed by reverse-phase HPLC using a Prominence LC solution system (Shimadzu) and photodiode array detector (SPD-M20A, Shimadzu) with Inertsil ODS3 (Shimadzu). The chromatographic conditions were as follows: solvent, $75 \%(\mathrm{v} / \mathrm{v})$ acetonitrile; column temperature $40^{\circ} \mathrm{C}$; flow rate, $1.2 \mathrm{~mL} \cdot \mathrm{min}^{-1}$. Retention times and spectra were compared with those of pure standards of quinic acid, malic acid, and citric acid. Results are expressed as milligrams per $100 \mathrm{~g}$ fresh weight $(\mathrm{FW})$. The measurement of sample extracts was replicated three times.

Anthocyanins. Total anthocyanin was measured using the pH differential method (Wrolstad, 1976). Freeze-dried fruit $(0.1 \mathrm{~g})$ were extracted with $10 \mathrm{~mL}$ of $100 \%(\mathrm{v} / \mathrm{v})$ methanol containing $1 \% \mathrm{HCl}$ and subjected to ultrasonic extraction for $15 \mathrm{~min}$. These extracts were passed through a $0.22-\mu \mathrm{m}$ membrane filter (Millipore) for analysis of total anthocyanins. Briefly, absorbance of the extract was measured at 510 and $700 \mathrm{~nm}$ in buffers at $\mathrm{pH}$ 1.0 (hydrochloric acid-potassium chloride, $0.2 \mathrm{~N}$ ) and 4.5 (acetate acid-sodium acetate, $1 \mathrm{M}$ ), respectively. Anthocyanin content was calculated using a molecular weight of cyanidin-3glucoside (Cy-glu) (449 g/mol), a molar extinction coefficient of Cy-glu $(29,600)$, and absorbance of $A=\left[\left(A_{510}-A_{700}\right)_{\mathrm{pH} 1.0}-\right.$ $\left.\left(A_{510}-A_{700}\right)_{\mathrm{pH} 4.5}\right]$ measured by a spectrophotometer (SmartSpec Plus; Bio-Rad Laboratories, Hercules, CA). The total anthocyanin content is expressed as milligrams Cy-glu equivalents per $100 \mathrm{~g} \mathrm{FW}$. The measurement of sample extracts was replicated three times.

HPLC was also used to separate anthocyanins and determine quantities of the individual anthocyanins in the samples. The extracts were analyzed by a reverse-phase HPLC Prominence LC solution system and photodiode array detector (SPD-M20A) with an STR-ODS column (Shimadzu). The chromatographic conditions were as follows: solvent A [1\% (v/v) phosphoric acid], solvent B [1\% (v/v) phosphoric acid, $50 \%(\mathrm{v} / \mathrm{v})$ methanol, and $0.1 \%(\mathrm{v} / \mathrm{v})$ trifluoroacetic acid], column temperature $40^{\circ} \mathrm{C}$, detection at $520 \mathrm{~nm}$, flow rate $1.4 \mathrm{~mL} \cdot \mathrm{min}^{-1}$. The column was equilibrated with $40 \% \mathrm{~B}$ before use. The binary gradient was as follows: $40 \%$ to $45 \% \mathrm{~B}$ (0-5 min), $45 \% \mathrm{~B}(5-10 \mathrm{~min}), 50 \% \mathrm{~B}$ (10-20 $\mathrm{min}), 50 \%$ to $78 \% \mathrm{~B}(20-25 \mathrm{~min}), 78 \%$ to $100 \% \mathrm{~B}$ (25-28 $\mathrm{min}), 100 \%$ B (28-33 $\mathrm{min}), 100 \%$ to $40 \%$ B (33-38 min). Retention times and spectra were compared with pure standards of cyanidin-3-glucoside and cyanidin-3-galactoside. Other putative anthocyanin peaks were presumed using the method of Chen et al. (2013), Toshima et al. (2017), and Veberic 
et al. (2015), and five anthocyanins were identified. The measurement of sample extracts was replicated three times.

Carotenoids. Carotenoid compositions were determined with HPLC, which was used to separate and identify individual carotenoids in the sample. The analysis of carotenoid contents was performed according to the method of Ishiguro et al. (2010). Three milliliters of acetone was added to freeze-dried fruit $(1 \mathrm{~g})$ in a centrifuge tube and mixed using a vortex mixer. The mixtures were centrifuged at $1500 \mathrm{~g}_{\mathrm{n}}$ for $10 \mathrm{~min}$. A $1-\mathrm{mL}$ aliquot of the upper layer of the supernatant was taken, and $3 \mathrm{~mL}$ of acetone was added to the rest. After reextracting, $3 \mathrm{~mL}$ of the upper layer was taken for analysis. The extract was evaporated to dryness under a stream of nitrogen gas, and the residue was redissolved in $1 \mathrm{~mL}$ of tetrahydrofuran containing $0.1 \%$ BHT and filtered through $0.2-\mu \mathrm{m}$ membrane filter (DISMIC13HP; ADVANTEC, Tokyo, Japan). The extracts were analyzed by reverse-phase HPLC using a Prominence LC solution system and photodiode array detector (SPD-M20A) with Wakopack Navi C30-5 (FUJIFILM Wako Pure Chemical Corp., Osaka, Japan). The chromatographic conditions were as follows: solvent A [acetonitrile:water (90:10) containing $0.05 \%$ triethylamine], solvent B [acetonitrile:methanol:chloroform $(75: 10: 15)$ containing $0.05 \%$ triethylamine], column temperature $35^{\circ} \mathrm{C}$, detection at 430 and $450 \mathrm{~nm}$, flow rate $0.425 \mathrm{~mL} \cdot \mathrm{min}^{-1}$. The binary gradient was as follows: $0 \%$ to $100 \% \mathrm{~B}(0-40 \mathrm{~min}), 100 \% \mathrm{~B}$ (40-80 $\mathrm{min}), 100 \%$ to $0 \% \mathrm{~B}(80-82 \mathrm{~min}), 0 \% \mathrm{~B}(82-120 \mathrm{~min})$. Retention times and spectra were compared with those of pure standards of lutein, $\beta$-cryptoxanthin, $\alpha$-carotene, and $\beta$-carotene. The results are expressed as micrograms per $100 \mathrm{~g} \mathrm{FW}$. The measurement of sample extracts was replicated three times.

Statistical analysis. All experimental results were means \pm SDs and were evaluated for statistical significance using univariate analysis of variance with statistical software (Statistica 13.0; StatSoft, Tulsa, OK) and Tukey's post hoc test. Differences were considered significant at the 5\% level. We compared with morphological characteristics and fruit compositions among cultivar and hybrids by Tukey's multiple range test.

\section{Results}

Growth AND Fruit CHARACTERISTICS. The IP-1 interspecific hybrid, the IPI-1 and IPI-3 (BC ${ }_{1}$ hybrids), and 'Indian Summer' red raspberry were planted in an unheated plastic greenhouse in a relatively warm region in Miyazaki, Japan, in Dec. 2016, and flowering and fruiting were confirmed in all cultivars or strains from the spring period of the following year. Both the FC and PC in each IPI line showed vigorous growth (Fig. 1A) and weak prickles
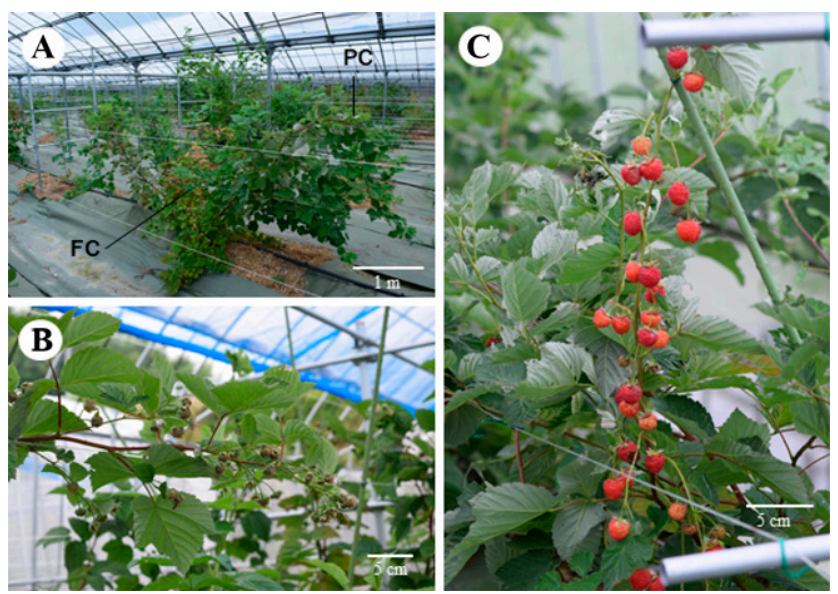

Fig. 1. The morphological characteristics of IPI-1, $\mathrm{BC}_{1}$ hybrids $[($ Rubus idaeus $\times$ Rubus parvifolius $) \times R$. idaeus $]$. (A) Floricane $(\mathrm{FC})$ and primocane (PC) on tree appearance at the beginning of June. (B) Young fruits on PC in the middle of June. (C) PC fruiting at the beginning of December.

on the cane. FC flowers of IP-1, the IPI lines, and 'Indian Summer' bloomed from early May, and fruiting began from early June. These plants developed flowers and fruit from the top few FC buds, and continued fruiting until late June. There was no PC flowering and fruiting of IP-1 or 'Indian Summer'; however, the PC flowering of IPI lines began in mid-May and fruiting was observed from mid-June. IPI lines had many fruit overflowing from side buds (Fig. 1B), and mature fruit were observed until September (Fig. 1C). By mid-December, IPI lines had completely shed their leaves and gone dormant. No significant differences in growth characteristics were observed between these two $\mathrm{BC}_{1}$ hybrids.

Morphological characteristics of FC and PC fruit of IPI-1 and IPI-3 and 'Indian Summer' red raspberry are shown in Table 1. Mature fruit of the IPI lines had a yellowish red color, lighter than that of 'Indian Summer' red raspberry (Fig. 2). No significant difference in berry weight was observed between $\mathrm{FC}$ fruit (IPI-1 $=4.80 \mathrm{~g}$; IPI-3 $=4.09 \mathrm{~g}$ ) and PC fruit (IPI-1 $=3.98 \mathrm{~g}$; IPI-3 $=4.11 \mathrm{~g}$ ) of each IPI line, but the berry weights of IPI lines were significantly higher (2.9- and 2.4-fold) than that of 'Indian Summer' (1.64 g). Similarly, berry length, diameter, and number of drupelets were significantly higher in IPI lines than 'Indian Summer', whereas there were no significant differences between the IPI lines and 'Indian Summer' in the weight of berry drupelets. The aggregate fruit of the IPI lines were thus considered as well formed as those of 'Indian Summer'.

SugarS AND ORGaNiC ACIDS. In all mature fruit tested, glucose, fructose, and sucrose were detected as shown in Fig. 3A. There

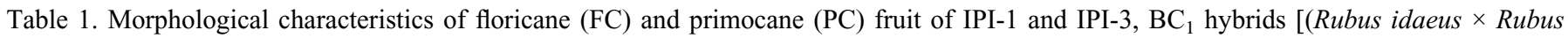
parvifolius $) \times R$. idaeus], and 'Indian Summer' red raspberry. ${ }^{\mathrm{z}}$

\begin{tabular}{|c|c|c|c|c|c|c|}
\hline \multirow{2}{*}{ Hybrids/cultivar } & Berry wt (g) & Berry length (mm) & Berry diam (mm) & Drupelets (no./berry) & Drupelet wt (g) & Seed wt (mg/berry) \\
\hline & \multicolumn{6}{|c|}{ mean $\pm \mathrm{SD}$} \\
\hline IPI-1 FC & $4.8 \pm 0.74 \mathrm{a}^{\mathrm{y}}$ & $21.9=$ & $21.7 \pm 1.66 \mathrm{a}$ & $90.2 \pm 2$ & $0.018 \mathrm{NS}$ & $1.77 \pm$ \\
\hline IPI-3 FC & $4.0 \pm 0.36 \mathrm{~b}$ & $19.9 \pm$ & $19.9 \pm$ & $30 \mathrm{ab}$ & 0.013 & $61 \mathrm{~b}$ \\
\hline IPI-1 PC & $4.1 \pm 0.74 \mathrm{ab}$ & $20.4 \pm 1.81 \mathrm{a}$ & $21.9 \pm 1.60 \mathrm{a}$ & $67.5 \pm 19.20 \mathrm{~b}$ & $0.061 \pm 0.018$ & $2.15 \pm 0.028 \mathrm{a}$ \\
\hline IPI-3 PC & $4.1 \pm 0.49 \mathrm{ab}$ & $21.2 \pm 1.19 \mathrm{a}$ & $21.5 \pm 1.33 \mathrm{ab}$ & $65.2 \pm 11.25 \mathrm{~b}$ & $0.064 \pm 0.012$ & $2.12 \pm 0.159 \mathrm{a}$ \\
\hline Indian Summer & $1.6 \pm 0.44 \mathrm{c}$ & $15.8 \pm 2.56 \mathrm{~b}$ & $16.5 \pm 1.08 \mathrm{c}$ & $28.0 \pm 9.21 \mathrm{c}$ & $0.056 \pm 0.013$ & $1.88 \pm 0.082 \mathrm{~b}$ \\
\hline
\end{tabular}

${ }^{\mathrm{z} B e r r y}$ weight, berry length, berry diameter, number of drupelets, and weight of berry drupelet $(\mathrm{n}=10)$; weight of seeds per berry weight $(\mathrm{n}=3)$.

${ }^{\mathrm{y}}$ Different letters represent significant differences at 5\% level as Tukey's multiple range test; ns = not significant. 
A
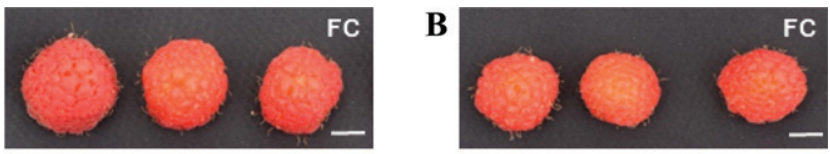

C

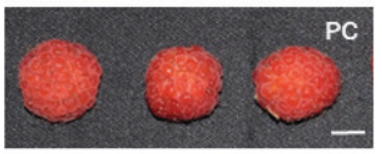

$\mathbf{E}$

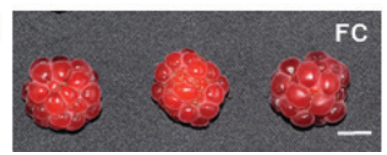

D

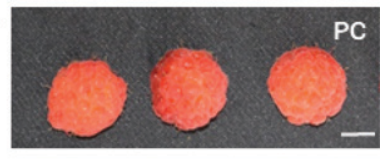

F

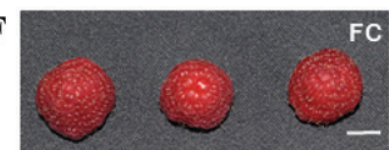

Fig. 2. The fruit characteristics. (A) IPI-1, $\mathrm{BC}_{1}-1$ hybrid $[($ Rubus idaeus $\times$ Rubus parvifolius $) \times R$. idaeus $]$ floricane (FC) fruit. (B) $\mathrm{IPI}-3, \mathrm{BC}_{1}-3$ hybrid $[(R$ idaeus $\times R$. parvifolius $) \times R$. idaeus] $\mathrm{FC}$ fruit. $(\mathbf{C})$ IPI-1 primocane $(\mathrm{PC})$ fruit. (D) IPI-3 PC fruit. (E) IP-1 interspecific hybrid ( $R$. idaeus $\times R$. parvifolius $)$ fruit. $(\mathbf{F})$ 'Skeena' red raspberry fruit. Bar $=1 \mathrm{~cm}$.

was no significant difference in total sugar content among cultivars or strains, years, and two types of canes, which ranged from 4.8 to $8.9 \mathrm{~g} / 100 \mathrm{~g} \mathrm{FW}$. Three types of organic acids (quinic acid, malic acid, and citric acid) were identified in all tested mature fruit (Fig. 3A), and total organic acids ranged from 1.9 to $2.6 \mathrm{~g} /$ $100 \mathrm{~g}$ FW without significant differences. The sugar/acid ratios of FC and PC fruit are shown in Fig. 3B, and those of FC fruit of IPI lines in 2018 (4.5 and 4.0 sugar/acid ratio, respectively) were higher than those of 'Skeena' (2.0 sugar/acid ratio). Although there were no significant differences in sugar or organic acid contents of all tested mature fruit, the sugar/acid ratios of FC fruit of IPI lines in 2018 were higher than those of 'Skeena'. From these results, it was inferred that the mature fruit of IPI lines are considered to have a good taste.

Anthocyanins. As a result, the anthocyanin contents of the 'Skeena' red raspberry and IP-1 hybrid were 18.8 and $15.3 \mathrm{mg}$ Cy-glu per $100 \mathrm{~g} \mathrm{FW}$, respectively, significantly higher than those of IPI backcrossed hybrids (6.26 to $9.64 \mathrm{mg} \mathrm{Cy}$-glu per $100 \mathrm{~g} \mathrm{FW}$ ), as shown in Fig. 4A. The anthocyanin contents of 'Skeena' and IP-1 were $\approx 2.5$ - and 2.0-fold as much as that of all IPI lines. There was no significant difference in total anthocyanin content between the FC and PC fruit of the IPI lines. In relation to anthocyanin content, the mature fruit of the IPI lines had a yellowish red color, whereas those of IP-1 and 'Skeena' were dark red (Fig. 2).

A

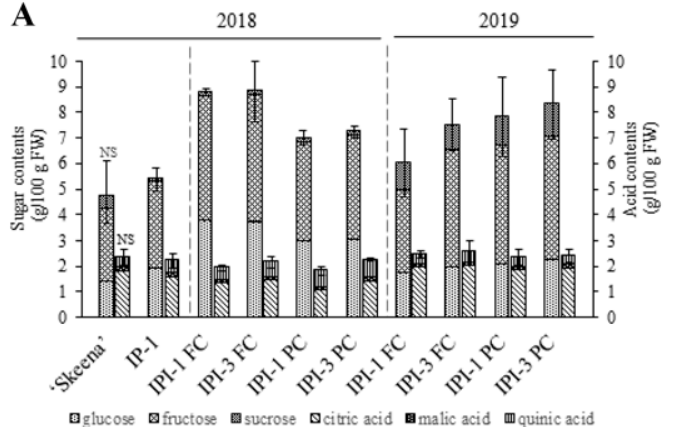

B

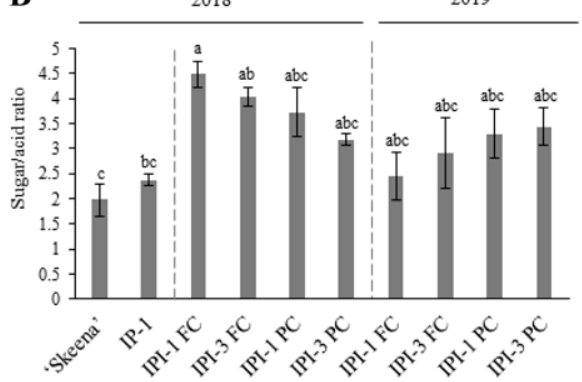

Fig. 3. (A) Sugar and organic acid contents and (B) sugar/acid ratio of floricane and primocane fruits of IP-1 interspecific hybrid (Rubus idaeus $\times$ Rubus parvifolius), IPI-1 and IPI-3, BC 1 hybrids [(R. idaeus $\times R$. parvifolius $) \times R$. idaeus], and 'Skeena' red raspberry harvested in 2018 and 2019. Different letters represent significant differences at $5 \%$ level as determined by Tukey's multiple range test $(\mathrm{n}=3)$. FC = floricane fruit; PC $=$ primocane fruit; NS $=$ not significant.

The anthocyanin compositions of $\mathrm{FC}$ and $\mathrm{PC}$ fruit were measured by HPLC, and the results are shown in Fig. 4B as the percentage distribution of anthocyanin. We detected four anthocyanins (cyanidin-3-sophoroside, cyanidin-3-glucosyl-rutinoside, cyanidin-3-glucoside, and cyanidin-3-rutinoside) in all fruit extracts. Cyanidin-3-glucoside was confirmed in all tested raspberries and hybrids. Mature fruit of IPI lines harvested in 2018 and 2019 contained high levels of cyanidin-3-glucosyl-rutinoside ( $29.5 \%$ to $29.7 \%$ ) and cyanidin-3-rutinoside $(26.8 \%$ to $46 \%)$ compared with 'Skeena' (15.6\% and 17\%, respectively), whereas the ratios of cyanidin-3-sophoroside $(9.7 \%$ to $14.5 \%)$ and cyanidin-3-glucoside $(8.0 \%$ to $12.7 \%)$ contained in mature fruit of IPI lines harvested in 2018 and 2019 had lower values than 'Skeena' ( $45.3 \%$ and $22.1 \%$, respectively).

Carotenoids. Fruit from IPI lines except for the 2018 FC fruit of IPI-1 had significantly higher (5-fold) total carotenoid content than that of 'Skeena' red raspberry $(53.0 \mu \mathrm{g} / 100 \mathrm{~g} \mathrm{FW})$, as shown in Fig. 5A. Among IPI lines, PC fruit from 2019 tended to have higher carotenoid contents.

Four carotenoids were identified from both $\mathrm{PC}$ and $\mathrm{FC}$ fruit: $\beta$-carotene, $\alpha$-carotene, $\beta$-cryptoxanthin, and lutein (Fig. 5B). The $\beta$-carotene content was lower in IPI lines $(25.8 \%$ to $35.8 \%)$ compared with that of 'Skeena' red raspberry $(54.5 \%)$ and the IP-1 hybrid (48.8\%), whereas $\alpha$-carotene was higher in IPI lines $(25.1 \%$ to $31.3 \%)$ compared with 'Skeena' red raspberry (13.2\%) and IP-1 hybrid (12.4\%). The percentage distribution of carotenoids was similar among the IPI lines of each harvested year and between PC and FC fruit.

\section{Discussion}

As the result, in addition to the adaptability of IPI- 1 and -3 to the moist warm climate of southern Japan, we were able to demonstrate their production of large and delicious fruit and the characteristic of the PC fruiting. Also, in our analysis of the morphology and taste of the fresh fruit, we found that the fruit weight, longitudinal diameter, and transverse diameter of the fresh fruit of IPI lines were significantly higher than those of the red raspberry. Especially, large size of fruit is one of the value traits in fruit qualities for the berry market and it is estimated that IPI lines were high quality fruit to be able to grow in southern Japan. In addition, the sugar/acid ratio of the fresh fruit of IPI lines in 2018 had higher values than that of red raspberry; therefore, the IPI lines were considered excellent lines, having a good taste and producing relatively large fruit.

Sugars and organic acids are important in driving consumer preference in red raspberry. Villamor et al. (2013) showed consumers had a more frequent preference for berries rated as sweet, and high scores for sourness and bitterness were negatively rated. The sugar components in raspberry fruit are mainly the monosaccharides glucose and fructose and the disaccharide sucrose (Lee, 2015; Mazur et al., 2014; Stavang et al., 2015). In addition, smaller amounts of xylose, 
A

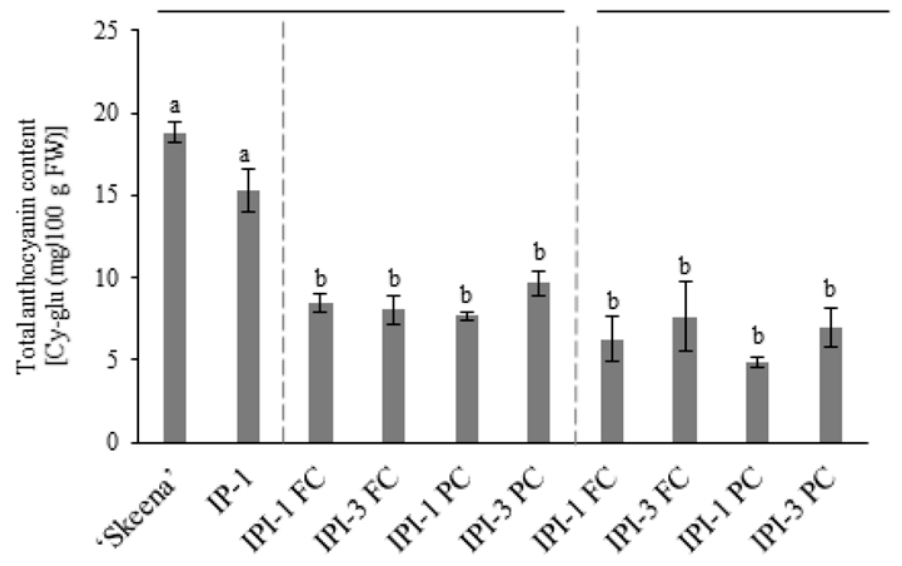

B

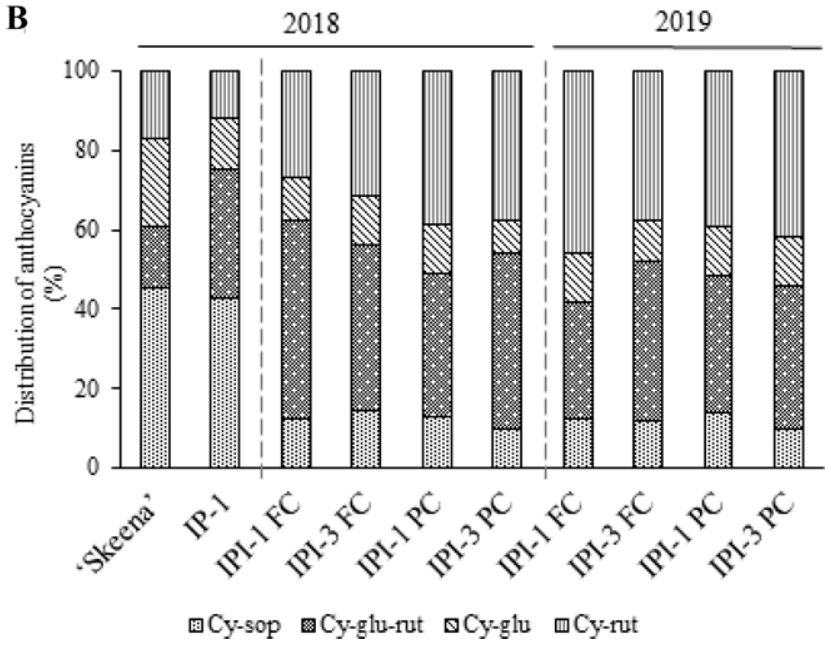

Fig. 4. (A) Total anthocyanin content and (B) percentage distribution of anthocyanins of floricane and primocane fruits of IP-1 interspecific hybrid (Rubus idaeus $\times$ Rubus parvifolius $)$, IPI-1 and IPI-3, $\mathrm{BC}_{1}$ hybrids $[($ R. idaeus $\times R$. parvifolius $) \times R$. idaeus] , and 'Skeena' red raspberry harvested in 2018 and 2019. Different letters represent significant differences at $5 \%$ level as determined by Tukey's multiple range test $(\mathrm{n}=3)$. $\mathrm{FC}=$ floricane fruit; $\mathrm{PC}=$ primocane fruit; Cy-glu = cyanidin-3-glucoside; Cy-sop = cyanidin-3-sophoroside; Cy-glu-rut = cyanidin-3-glucosyl-rutinoside; Cy-rut = cyanidin-3-rutinoside .

trehalose, myo-inositol (Dincheva et al., 2013), sorbitol, and mannitol (Lee, 2015) have also been reported. Generally, fructose has a higher relative sweetness than glucose and sucrose (McBride, 1986). In this study, the fruit of the IPI lines had not only a high content of fructose, which is perceived as sweeter than the other two sugars detected, but also a higher sugar/acid ratio than 'Skeena' red raspberry. In strawberry breeding, it has been clarified that cultivars with a high fructose ratio as well as the taste and the aroma have potential as new promising cultivars (Kafkas et al., 2007). Increasing the fructose content and its proportion of red raspberry fruit may make it a more consumer-preferred cultivar.

In this study, the carotenoid content was significantly higher in IPI lines than in 'Skeena'. In terms of composition, the IPI lines had a higher ratio of $\alpha$-carotene and a lower ratio of lutein compared with 'Skeena'. In a previous study, raspberry and blackberry fruit were shown to contain lutein, $\beta$-cryptoxanthin, $\beta$-carotene, and $\alpha$-carotene (Bradish et al., 2015; Carvalho et al., 2013; Marinova and Ribarova, 2007), and these compositions were also detected in the fruit of 'Skeena' raspberry, $R$. parvifolius, and IPI lines. On the other hand, the main carotenoid in raspberry fruit is lutein (Beekwilder et al., 2008; Marinova and Ribarova, 2007), whereas this result differed in our study about proportion of carotenoids. IPI lines are a first backcross of the interspecific hybrid between 'Indian Summer' red raspberry and $R$. parvifolius, and have a different genome from the cultivated species. Mizuno et al. (2017) investigated Japanese wild species including $R$. parvifolius for $\beta$-cryptoxanthin content, and R. parvifolius had a significantly higher content than that of cultivated species. Carotenoid compositions and amounts differ among different Rubus species; thus, IPI lines showed different compositions compared with 'Skeena'. Studies of carotenoids in Rubus
A

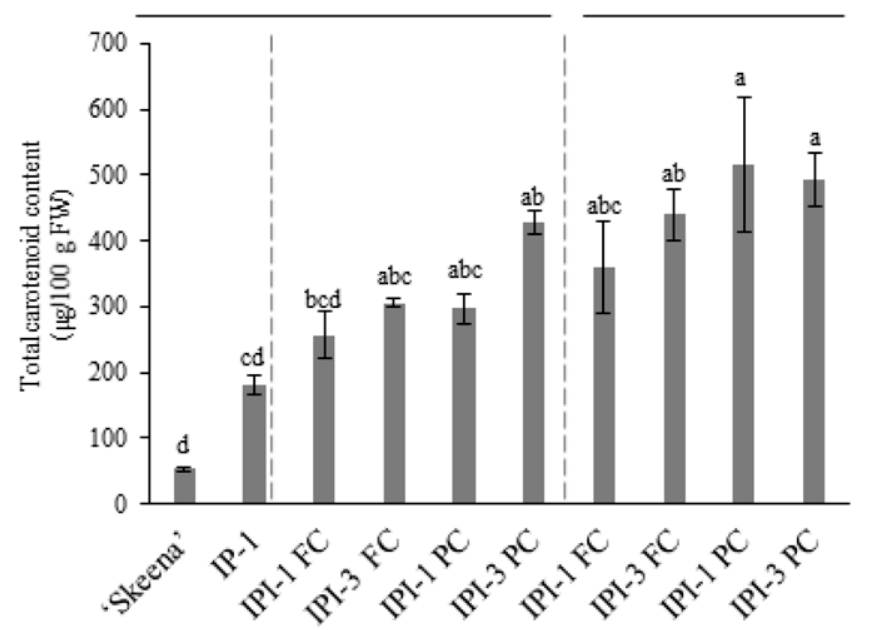

B

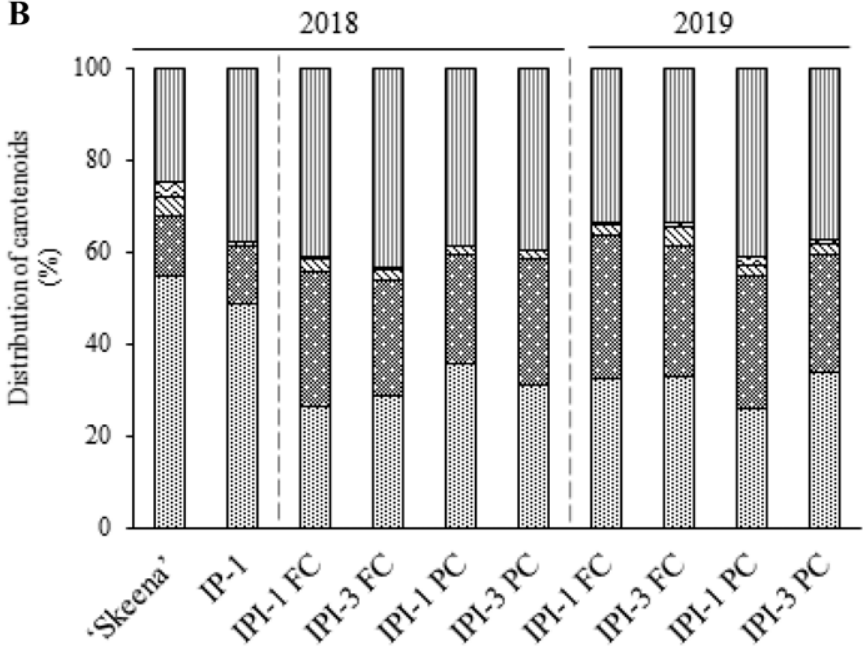

田 $\beta$-carotene $\alpha$-carotene $\$ \beta$-cryptoxanthin dlutein $\square$ unknown

Fig. 5. (A) Total carotenoid content and (B) percentage distribution of carotenoids of floricane and primocane fruits of IP-1 interspecific hybrid (Rubus idaeus $\times$ Rubus parvifolius $)$, IPI-1 and IPI-3, $\mathrm{BC}_{1}$ hybrids [(R. idaeus $\times$ R. parvifolius $) \times R$. idaeus], and 'Skeena' red raspberry harvested in 2018 and 2019 . Different letters represent significant differences at $5 \%$ level as determined by Tukey's multiple range test $(\mathrm{n}=3)$. $\mathrm{FC}=$ floricane fruit; $\mathrm{PC}=$ primocane fruit. 
species were not major than those of anthocyanins, and this report could contribute as advancing lipophilic functional components in cultivars and wild species.

In the present study, IPI-1 and IPI-3, $\mathrm{BC}_{1}$ hybrids of the interspecies 'Indian Summer' red raspberry and $R$. parvifolius hybrid, were selected and analyzed for traits and fruit composition over 2 years. In conclusion, IPI-1 and IPI-3 were capable of growing in warm regions of Japan and were shown to be superior to the 'Indian Summer' red raspberry because of their larger fruit size and PC fruiting. Although the anthocyanin contents in fruit of IPI lines were significantly lower than that of 'Skeena', the carotenoid content was significantly higher in the IPI lines, with the exception of FC of IPI-1. Recently, $R$. parvifolius, which was used to develop IPI-1, has been attracting attention as one of the promising wild materials for breeding of raspberry in Asia. Polyphenols and saponins in the fruit of $R$. parvifolius have been shown to possess antimicrobial activity and an antitumor effect (Cao et al., 2021; Seleshe et al., 2017). Also, R. parvifolius has undergone genetic analysis using DNA markers as breeding material in Asia (Miyashita et al., 2015; Wang et al., 2018), and was used for identifying molecular markers associated with traits such as fruit size and chilling requirement by quantitative trait loci (Molina-Bravo et al., 2014). Thus, R. parvifolius should be an effective material for cross breeding and formation construction of a linkage map for beneficial traits like fruit size and adaptability to climates among Rubus species. Our results suggest that Asian wild species, including $R$. parvifolius as a new genetic resource, hold promise for future raspberry breeding.

\section{Literature Cited}

Alibabic, V., A. Skender, M. Bajramovic, E. Sertovic, and E. Bajric. 2018. Evaluation of morphological, chemical, and sensory characteristics of raspberry cultivars grown in Bosnia and Herzegovina. Turk. J. Agr. For. 42:67-74, https://doi.org/10.3906/tar-1702-59.

Beekwilder, J., I.M. Van Der Meer, A. Simic, J. Uitdewilligen, J. Van Arkel, R.C. De Vos, and R.D. Hall. 2008. Metabolism of carotenoids and apocarotenoids during ripening of raspberry fruit. Biofactors 34(1):57-66.

Bradish, C.M., G.G. Yousef, G. Ma, P. Perkins-Veazie, and G.E. Fernandez. 2015. Anthocyanin, carotenoid, tocopherol, and ellagitannin content of red raspberry cultivars grown under field or high tunnel cultivation in the southeastern United States. J. Amer. Soc. Hort. Sci. 140:163-171, https://doi.org/10.21273/JASHS.140.2.163.

Burton-Freeman, B.M., A.K. Sandhu, and I. Edirisinghe. 2016. Red raspberries and their bioactive polyphenols: Cardiometabolic and neuronal health links. Adv. Nutr. 7:44-65, https://doi.org/10.3945/ an.115.009639.

Cao, J., X. Zhao, Y. Ma, J. Yang, and F. Li. 2021. Total saponins from Rubus parvifolius L. inhibits cell proliferation, migration and invasion of malignant melanoma in vitro and in vivo. Biosci. Rep. 41(1):BSR20201178, https://doi.org/10.1042/BSR20201178.

Carvalho, E., P.D. Fraser, and S. Martens. 2013. Carotenoids and tocopherols in yellow and red raspberries. Food Chem. 139:744-752, https://doi.org/10.1016/j.foodchem.

Chen, L., X. Xin, H. Zhang, and Q. Yuan. 2013. Phytochemical properties and antioxidant capacities of commercial raspberry varieties. J. Funct. Foods 5:508-515, https://doi.org/10.1016/j.jff.2012.10.009.

Clark, J.R., B.C. Strik, E. Thompson, and C.E. Finn. 2012. Progress and challenges in primocane-fruiting blackberry breeding and cultural management. Acta Hort. 926:387-392, https://doi.org/10.17660/ ActaHortic.2012.926.54.

Clark, J.R., C. McCall, and C.E. Finn. 2008. Blackberry, p. 1323-1324. In: C.E. Finn and J.R. Clark (eds.). Register of new fruit and nut cultivars. Amer. Soc. Hort. Sci., Alexandria, VA.
Dai, H., S. Liu, and D. Xiao. 2015. Botanical traits and cold hardiness of interspecific hybrids between European and Chinese raspberries. Acta Hort. 1133:61-66, https://doi.org/10.17660/ActaHortic.2016.1133.10.

Dincheva, I., I. Badjakov, V. Kondakova, and R. Batchvarova. 2013. Metabolic profiling of red raspberry (Rubus idaeus) during fruit development and ripening. Int. J. Agr. Sci. Res. (Chennai) 3:81-88.

de Ancos, B., E. Gonzalez, and M.P. Cano. 1999. Differentiation of raspberry varieties according to anthocyanin composition. Z. Lebensm. Unters. Forsch. A 208:33-38, https://doi.org/10.1007/s002170050371.

Finn, C.E. and J.R. Clark. 2014. Blackberry, p. 399-400. In: K. Gasic and J.E. Preece (eds.). Register of new fruit and nut varieties. Amer. Soc. Hort. Sci., Alexandria, VA.

Gu, Y., W. Jin, C.M. Zhao, and S.A. He. 1990. Rubus resources in Fujian and Hunan provinces. Acta Hort. 345:117-126, https://doi. org/10.17660/ActaHortic. 1993.345.16.

Heide, O.M. and A. Sønsteby. 2011. Physiology of flowering and dormancy regulation in annual-and biennial-fruiting red raspberry (Rubus idaeus L.) - A review. J. Hort. Sci. Biotechnol. 86:433-442, https://doi.org/10.1080/14620316.2011.11512785.

Hummer, K.E., J.R. Ballington, C.E. Finn, and T.M. Davis. 2013. Asian germplasm influences on American berry crops. J. Amer. Soc. Hort. Sci. 48:1090-1094, https://doi.org/10.21273/HORTSCI.48.9.1090.

Imanishi, H. and T. Miyairi. 2015. Development of a production area and long-term harvesting of red raspberries using plastic greenhouses in Japan. Acta Hort. 1133:189-194, https://doi.org/10.17660/ActaHortic. 2016.1133.28.

Ishiguro, K., M. Yoshinaga, Y. Kai, T. Maoka, and M. Yoshimoto. 2010. Composition, content and antioxidative activity of the carotenoids in yellow-fleshed sweetpotato (Ipomoea batatas L.). Breed. Sci. 60:324-329, https://doi.org/10.1270/jsbbs.60.324.

Jennings, D.L. 1995. Raspberries and blackberries, p. 429-434. In: J. Smartt and N.W. Simmonds (eds.). Evoluation of crop plants. Longman, Harlow, UK.

Kafkas, E., M. Koşar, S. Paydaş, S. Kafkas, and K.H.C. Başer. 2007. Quality characteristics of strawberry genotypes at different maturation stages. Food Chem. 100:1229-1236, https://doi.org/10.1016/j. foodchem.2005.12.005.

Lee, J. 2015. Sorbitol, Rubus fruit, and misconception. Food Chem. 166:616-622, https://doi.org/10.1016/j.foodchem.2014.06.073.

Marinova, D. and F. Ribarova. 2007. HPLC determination of carotenoids in Bulgarian berries. J. Food Compos. Anal. 20:370-374, https://doi.org/10.1016/j.jfca.2006.09.007.

Mazur, S.P., A. Sønsteby, A. Nes, A.B. Wold, A. Foito, S. Freitag, S. Verrall, S. Stewart, and O.M. Heide. 2014. Effects of post-flowering environmental variation along an altitudinal gradient on chemical composition of 'Glen Ample' red raspberry (Rubus idaeus L.). Eur. J. Hort. Sci. 79:267-277.

McBride, R.L. 1986. Sweetness of binary mixtures of sucrose, fructose, and glucose. J. Exp. Psychol. Hum. Percept. Perform. 12(4):584-591, https://doi.org/10.1037/0096-1523.12.4.584.

Miyashita, T., H. Kunitake, N. Yotsukura, and Y. Hoshino. 2015. Assessment of genetic relationships among cultivated and wild Rubus accessions using AFLP markers. Scientia Hort. 193:165-173, https://doi.org/10.1016/j.scienta.2015.07.004.

Mizuno, K., T. Tokiwano, and Y. Yoshizawa. 2017. Gene expression analysis of enzymes of the carotenoid biosynthesis pathway involved in $\beta$-cryptoxanthin accumulation in wild raspberry, Rubus palmatus. Biochem. Biophys. Res. Commun. 484:845-849, https://doi.org/ 10.1016/j.bbrc.2017.01.186.

Molina-Bravo, R., G.E. Fernandez, and B.R. Sosinski. 2014. Quantitative trait locus analysis of tolerance to temperature fluctuations in winter, fruit characteristics, flower color, and prickle-free canes in raspberry. Mol. Breed. 33(2):267-280, https://doi.org/10.1007/s11032-013-99 47-4.

Moore, P.P. and C. Kempler. 2012. Raspberry, p. 555-556. In: C.E. Finn and J.R. Clark (eds.). Register of new fruit and nut cultivars. Amer. Soc. Hort. Sci., Alexandria, VA. 
Pritts, M. 2008. Primocane-fruiting raspberry production. J. Amer. Soc. Hort. Sci. 43:1640-1641, https://doi.org/10.21273/HORTSCI.43.6.1640.

Seleshe, S., J.S. Lee, S. Lee, H.J. Lee, G.R. Kim, J. Yeo, J.Y. Kim, and S.N. Kang. 2017. Evaluation of antioxidant and antimicrobial activities of ethanol extracts of three kinds of strawberries. Prev. Nutr. Food Sci. 22(3):203-210, https://doi.org/10.3746/pnf.2017.22.3.203.

Skrovankova, S., D. Sumczynski, J. Mlcek, T. Jurikova, and J. Sochor. 2015. Bioactive compounds and antioxidant activity in different types of berries. Int. J. Mol. Sci. 16:24673-24706, https://doi.org/ 10.3390/ijms161024673.

Stanys, V., V. Bendokas, R. Rugienius, A. Sasnauskas, B. Frercks, I. Mažeikienè, and T. Šikšnianas. 2019. Management of anthocyanin amount and composition in genus Ribes using interspecific hybridisation. Scientia Hort. 247:123-129, https://doi.org/10.1016/j.scienta. 2018.12.014.

Stavang, J.A., S. Freitag, A. Foito, S. Verrall, O.M. Heide, D. Stewart, and A. Sønsteby. 2015. Raspberry fruit quality changes during ripening and storage as assessed by colour, sensory evaluation and chemical analyses. Scientia Hort. 195:216-225, https://doi.org/10.1016/j. scienta.2015.08.045.

Szajdek, A. and E.J. Borowska. 2008. Bioactive compounds and health-promoting properties of berry fruits: A review. Plant Foods Hum. Nutr. 63:147-156, https://doi.org/10.1007/s11130-008-0097-5.

Toshima, S., R. Okamoto-Nakamura, K. Abe, U. Sakazaki, H. Komatsu, and H. Kunitake. 2017. Growth characteristics and fruit qualities of interspecific hybrid between 'Indian Summer' raspberry and Rubus parvifolius L. (in Japanese with English abstract). J. Jpn. Soc. Hort. Sci. 16:345-352, https://doi.org/10.2503/hrj.16.345.

Toshima, S., T. Hirano, and H. Kunitake. 2021. Comparison of anthocyanins, polyphenols, and antioxidant capacities among raspberry, blackberry, and Japanese wild Rubus species. Scientia Hort. 285:110204, https://doi.org/10.1016/j.scienta.2021.110204.

Veberic, R., A. Slatnar, J. Bizjak, F. Stampar, and M. Mikulic-Petkovsek. 2015. Anthocyanin composition of different wild and cultivated berry species. Lebensm. Wiss. Technol. 60:509-517, https://doi.org/ 10.1016/j.lwt.2014.08.033.

Villamor, R.R., C.H. Daniels, P.P. Moore, and C.F. Ross. 2013. Preference mapping of frozen and fresh raspberries. J. Food Sci. 78:911-919, https://doi.org/10.1111/1750-3841.12125.

Wang, Y., W. He, J. Zhang, T. Chen, Q. Chen, H.R. Tang, L. Liu, and W.R. Wang. 2018. Genetic relationship between Rubus parvifolius and $R$. coreanus (Rubus, Rosaceae) based on simple sequence repeat markers, p. 101-109. In: 2017 2nd Intl. Conf. Biol. Sci. Technol. (BST 2017). Atlantis Press, Paris, France.

Wrolstad, R.E. 1976. Color and pigment analyses in fruit products. Oregon State Univ. Agr. Exp. Sta. Bull. 624.

Yang, J., J. Cui, J. Chen, J. Yao, Y. Hao, Y. Fan, and Y. Liu. 2020. Evaluation of physicochemical properties in three raspberries (Rubus idaeus) at five ripening stages in northern China. Scientia Hort. 263:109146, https://doi.org/10.1016/j.scienta.2019.109146. 